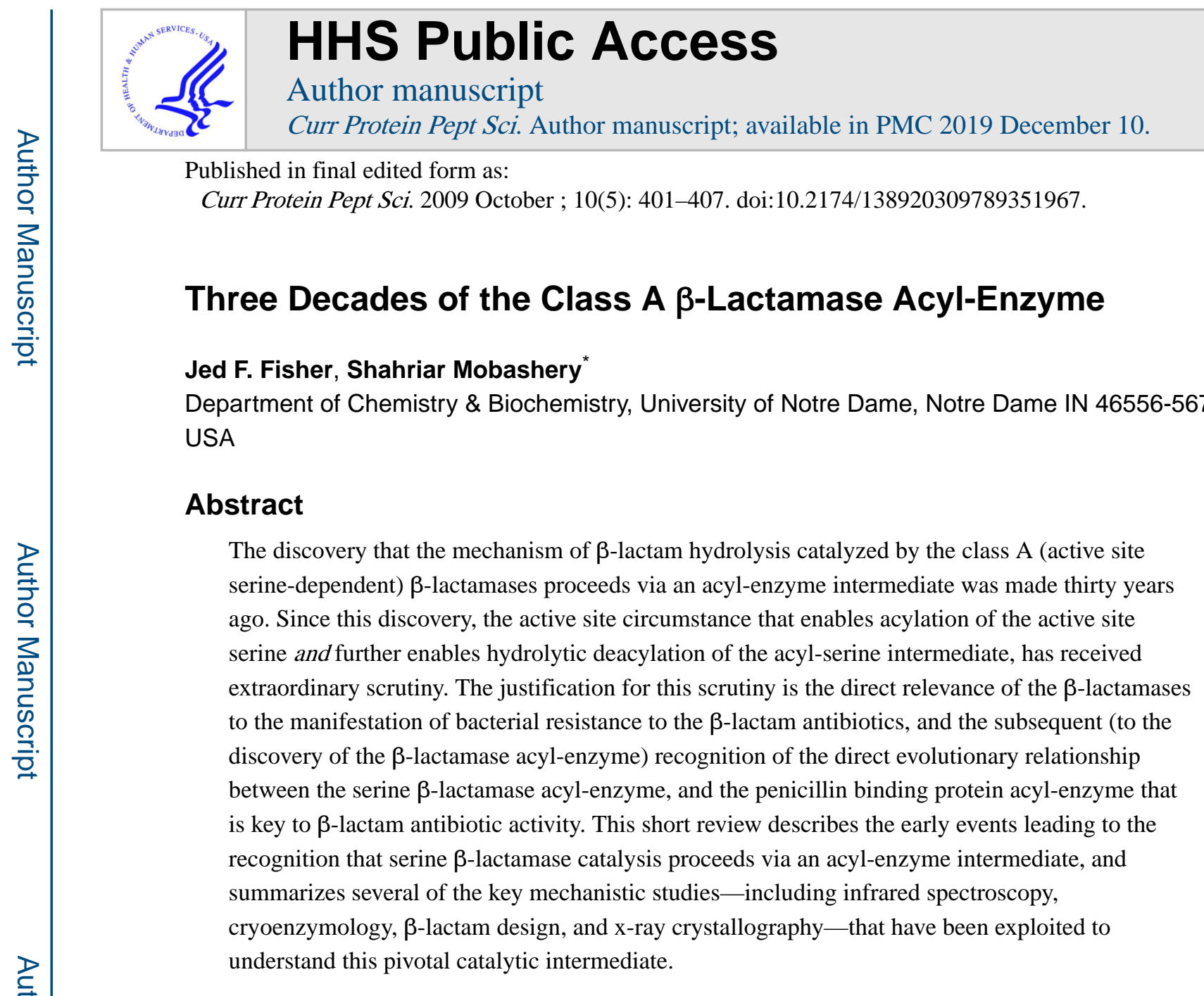

\title{
INTRODUCTION
}

The discovery of actinomycin by Waksman and Tishler in 1942 marks the birth of the antibiotic era [1]. Following the arrival of the next two classes of practical antibiotics, the aminoglycosides and the $\beta$-lactams, a revolutionary change occurred in the clinical treatment of bacterial infection. Of all of the antibiotic classes within this era, continuing to today, it is the $\beta$-lactams that are the most prominent. The decisive impact of the $\beta$-lactam class (first the penicillin subclass, then followed by the cephalosporin and carbapenem sub-classes) on human health is the consequence of their extraordinary efficacy and safety. This consequence follows from the uniqueness to the bacteria of the molecular target of the $\beta$ lactams: the enzyme catalysts of bacterial cell wall biosynthesis. During this biosynthesis, a key event is the cross-linking of the peptide branches of the peptidoglycan biosynthetic precursor, thus creating the polymeric surface of the bacterial cell wall. The mechanism used in this structurally critical cross-linking is acylation of an active site serine, via transacylation using the D-Ala-D-Ala terminus of the peptide branch, followed by a second acyl transfer to the amine of a neighboring branch. These biosynthetic enzymes accept the $\beta$ lactam as a structural analog of the D-Ala-D-Ala terminus (the Tipper-Strominger

*Address correspondence to this author at the Department of Chemistry \& Biochemistry, University of Notre Dame, Notre Dame IN 46556-5670, USA; smobashe@nd.edu. 
hypothesis), and efficiently engage the $\beta$-lactam as an acyl donor for the active site serine. A comparison of the D-Ala-D-Ala structure and a penicillin $\beta$-lactam is shown in Fig. (1). The D-Ala-D-Ala perspective shown is that described by Lee [2] and extensively discussed by Pratt [3]. The $\beta$-lactam derived acyl-enzyme is poorly capable of either transfer of its acylenzyme to the peptide (transpeptidation), or to water (regenerating active enzyme by acylenzyme hydrolysis). The enzyme is inactivated. The characteristic covalent labeling of these enzymes by the $\beta$-lactams, first observed by Strominger [4], is acknowledged in the continued use of "penicillin binding protein" (PBP) to describe these enzymes.

While strong arguments remain favoring the purpose of the evolutionary creation of the $\beta$ lactams by the bacteria and fungi that biosynthesize these antibiotics, as a chemical mechanism to ensure dominance within their ecological niche, it is now increasingly recognized that bacteria may also use small molecules for the purpose of communication. In either capacity, the existence of a companion biological mechanism to either destroy the antibiotic or to attenuate the signal, is anticipated. Indeed, prior to any clinical use of the $\beta$ lactams as antibiotics, the observation of the existence of such an enzymatic mechanism was made [5]. The molecular nature of this mechanism is now well understood, especially as it now also coincides with a primary mechanism for $\beta$-lactam resistance by pathogenic bacteria. This mechanism is enzyme-catalyzed hydrolysis of the $\beta$-lactam antibiotic, using water as a nucleophile to open the $\beta$-lactam ring, and to give an innocuous $\beta$-amino acid as product. These catalysts of $\beta$-lactam hydrolysis are called $\beta$-lactamases. Four subclasses of the $\beta$-lactamases are recognized, and three of these four share mechanistic commonality: an active site serine, and an acyl-enzyme intermediate in catalysis [6]. Knox has written an engaging historical perspective on the early history of the $\beta$-lactamases [7]. This short review traces the historical interrelationship between these two acyl-enzymes (that of the $\beta$ lactam-inactivated penicillin binding protein, and that of the $\beta$-lactamase catalytic intermediate), with specific focus on the exquisite mechanistic study that has been done on the $\beta$-lactamase acyl-enzyme in the thirty years following its discovery.

\section{DISCOVERY OF THE $\beta$-LACTAMASE ACYL-ENZYME}

For decades after their discovery, the structural and mechanistic characteristics of the $\beta$ lactamases were enigmatic. The first steps toward a mechanistic understanding of the $\beta$ lactamases were the result of a confluence, some thirty years ago, of several remarkable events. Using the Maxam-Gilbert method for the chemical sequencing of DNA, Sutcliffe determined the DNA sequence of the ampicillin resistance plasmid encoding a class A, active site-serine containing $\beta$-lactamase. From this DNA sequence the amino acid sequence of the $\beta$-lactamase (including the signal sequence governing its passage through the cytoplasmic membrane of the bacterium) was derived, as the first example of gene sequencing of a protein [8]. Although sequence homology between the PBP and the $\beta$ lactamase was low, similarity with respect to the key serine-containing tryptic peptide [9] immediately suggested an evolutionary relationship $[10,11]$. At the same time, the structural breadth of the $\beta$-lactam families was expanding dramatically beyond that of the penicillins and cephalosporins, to include the naturally occurring 7a-methoxy-substituted cephalosporins (cephamycins) [12], carbapenems [13], and clavulanate [14, 15]. The key aspects of the biological activity of each of these three classes coincided with a mechanistic 
ability to confound the hydrolytic catalysis of the serine-dependent $\beta$-lactamases. Moreover, this "confounding" ability was also imbued into two semisynthetic $\beta$-lactam classes, those of the 6-halo-substituted penicillins [16-20] and the penicillin sulfones [21]. In each of these examples, mechanistic expression of the confounding of the $\beta$-lactamase occurs through a pivotal acyl-enzyme intermediate [22]. The cephamycin and carbapenem acyl-enzymes resist hydrolytic deacylation by the presence of unprecedented functional group substitution. Clavulanate, the penicillin sulfones, and the 6-halopenicillins resist hydrolytic deacylation by competitive (with respect to hydrolysis) rearrangement of the acyl-enzyme to give hydrolytically incompetent acyl-enzyme structures. Transformation of a hydrolytically competent acyl-enzyme into a hydrolytically incompetent acyl-enzyme abolishes $\beta$ lactamase catalytic activity. Thus in the co-presence of an efficient $\beta$-lactam inactivator of the penicillin binding proteins, and an efficient inactivator of the $\beta$-lactamase, a bacterium with dependence on the $\beta$-lactamase for $\beta$-lactam resistance, is now rendered $\beta$-lactam susceptible.

For this reason alone, scientific scrutiny of the $\beta$-lactamase acyl-enzyme would be deemed highly desirable. Equally compelling justifications soon were discovered. Comparison of the protein domain arrangement of the serine-dependent $\beta$-lactamases [23], to that of the transpeptidase domain of the penicillin binding proteins, confirmed the predicted structural homology $[24,25]$. In particular, the active sites of these two enzymes organize a very similar, and remarkably intricate, array of hydrogen-bonding functionality around their respective scissile amides [26-28]. The commonality of PBP and serine $\beta$-lactamase active sites includes an ...SXXK... motif (containing the nucleophilic serine), an ...(S/Y)XN... motif, and a ...(K/H)T(S/G)... motif [29]. The most prominent distinguishing feature between the PBP and the class A (and C) serine $\beta$-lactamases is an additional active site loop (termed the $\Omega$-loop) that thrusts the sidechain of a glutamate into the active site, also enabling the sequestration of a water molecule between the glutamate and the lysine of the first motif. An alternative carboxylate structure is found in the class $D$ serine $\beta$-lactamases [30]. A two-dimensional representation of the key sidechains found in the class A $\beta$ lactamase active site is shown in Fig. (2), using the numbering system of the highly representative "TEM" $\beta$-lactamase (Ser70 and Lys73 of the SXXK motif, the Ser130 of an SXN motif, the Lys234 of the KTS motif, and the Glu166 of the $\Omega$-loop). The mainchain amide NH bonds of Ser70 and Ala237 comprise the oxyanion hole [31] into which the $\beta$ lactam carbonyl embeds.

The TEM $\beta$-lactamase is a plasmid- encoded class A serine $\beta$-lactamase of the Gram negative bacteria, and is closely related to class A $\beta$-lactamases of the Gram positive bacteria. Both are "fully efficient" enzymes showing a $k_{\text {cat }} / K_{\mathrm{M}}$ (equal to the diffusioncontrolled bimolecular rate constant) when evaluated with many common penicillins [32]. These two $\beta$-lactamases were used (virtually interchangeably) for early mechanistic study. The pivotal experiment toward the first observation of the class A acyl-enzyme followed an otherwise routine examination of the catalytic competence of the TEM $\beta$-lactamase toward penicillin-related structures [33]. Chemical reaction of benzylpenicillin with Raney nickel accomplishes, in good yield, reductive desulfurization while preserving the $\beta$-lactam substructure. The structure of this "des-thio" product, using benzylpenicillin as a reactant, is shown in Fig. (3). These monocyclic $\beta$-lactams are notably more stable to hydrolysis 
compared to the parent penicillin, and lack antibiotic activity. Nonetheless, exposure of the des-thio $\beta$-lactam to the TEM $\beta$-lactamase resulted in the slow-but certain $-\beta$-lactamasecatalyzed hydrolytic opening of its $\beta$-lactam. The irrefutable conclusion was that this $\beta$ lactamase recognized, and hydrolyzed, even a relatively stable $\beta$-lactam structure [34]. This realization stimulated several additional experiments. Addition of a small portion of the reaction mixture between the desthio $\beta$-lactam and the $\beta$-lactamase, into a solution of benzylpenicillin (a very much better substrate of the $\beta$-lactamase), showed the expected kinetic progress curve for benzylpenicillin hydrolysis. This appearance of ordinary $\beta$ lactamase kinetics was in contrast to the behavior seen for a $\beta$-lactamase-clavulanate acid (a $\beta$-lactam then undergoing concurrent experimental examination as a $\beta$-lactamase inactivator) reaction mixture $[35,36]$. While this experiment indicated that the only difference between desthiobenzylpenicillin and benzylpenicillin was very different hydrolysis rates, the possibility remained that other $\beta$-lactams purported to exhibit exceptional $\beta$-lactamase stability might also impart deviant kinetic behavior to $\beta$-lactamase. The critical experiment was with cefoxitin, a semi-synthetic cephamycin having the unusual 7a-methoxy substitution to a cephalosporin $\beta$-lactam [37, 38]. Dilution of a $\beta$-lactamase-cefoxitin reaction mixture into a solution of excess benzylpenicillin showed a first-order kinetic relaxation, from initially very slow hydrolysis progressing to $V_{\max }$ for hydrolysis of benzylpenicillin. Single-turnover experiments showed a burst of cefoxitin hydrolysis proportional to the $\beta$-lactamase stoichiometry [39]. The conclusion from these experiments was that cefoxitin was indeed an exceptionally poor $\beta$-lactamase substrate, and that an intermediate was formed during its $\beta$-lactamase-catalyzed hydrolysis. The kinetic mechanism for this hydrolysis was the more rapid formation of an intermediate, followed by slower transformation of this intermediate to complete turnover. An obvious chemical assignment for this intermediate was that of a serine acyl-enzyme.

This conclusion now has been proven by a host of experimental data, Indeed, the similarities and contrasts governing the pivotal mechanistic roles of the acyl-enzymes of serine $\beta$ lactamase, and also of PBP catalysis, constitute in the two decades following the structural solution of these structures, an entire literature unto itself. Within this literature our focus here is the $\beta$-lactamase acyl-enzyme, written from the vantage of the cefoxitin experiment and with particular recognition of the incisive insight brought to the understanding of the $\beta$ lactamase acyl-enzyme by Tony Fink and his colleagues.

\section{THE $\beta$-LACTAMASE ACYL-ENZYME AS A CATALYTIC INTERMEDIATE}

Direct evidence for the structural assignment of this intermediate as an acyl-enzyme was obtained with infrared spectroscopy, wherein two new bands arising from the cefoxitin- $\beta$ lactamase complex were observed at $1738 \mathrm{~cm}^{-1}$ and $1755 \mathrm{~cm}^{-1}$ [39]. Clarification of the assignments for these bands was made subsequently by Fink and colleagues, in an exquisitely executed series of experiments exploiting hydrated thin-film hydrated FTIR examination of several $\beta$-lactamase acyl-enzymes [40]. A key feature of Fink's study was the use of an acylation-defective mutant $\beta$-lactamase, having a Ser70Ala mutation. The replacement of Ser70 with alanine removes the nucleophilic hydroxyl of the serine, impairing catalysis but having no effect on the thermal stability of the enzyme (identical $T_{\mathrm{M}}$ values are seen for the native and Ser70Ala mutant enzymes). Using the Ser70Ala mutant, 
the carbonyl stretch at $1755 \mathrm{~cm}^{-1}$ was unambiguously assigned to the enzyme-bound $\beta$ lactam. Deuterium labeling confirmed correct placement of the $\beta$-lactam carbonyl within its oxyanion hole. Using cefoxitin as a substrate for the wild type enzyme, the $1738 \mathrm{~cm}^{-1}$ band could be assigned to the acyl-enzyme. Hokensen et al. interpret the approximately $13 \mathrm{~cm}^{-1}$ decrease in the carbonyl stretch when the $\beta$-lactam is enzyme-bound, compared to the free $\beta$-lactam, as a direct indication of enzyme-induced strain/distortion in the ground state of the bound $\beta$-lactam. The magnitude of this oxyanion hole-induced effect is as much as a $6 \mathrm{~kJ}$ $\mathrm{mol}^{-1}$ progression toward the transition state for acylation [41, 42].

Complementary evidence in support of a kinetically competent $\beta$-lactam- $\beta$-lactamase acylenzyme was obtained using low-temperature cryoenzymology [43, 44]. Using a chromophoric $\beta$-lactam, Cartwright et al. [45] observed appreciable accumulation of a $\beta$ lactam derived covalent intermediate using a 7:3 methanol/water solvent at $-40{ }^{\circ} \mathrm{C}$. The $\beta$ lactamase enzyme is fully stable under these conditions. Cold temperature acid denaturation of this intermediate, followed by pepsin/trypsin digestion, led to the isolation of a labeled peptide. This peptide contained the Ser70 residue [46]. This same peptide was labelled by the mechanism-based penicillin sulfone $\beta$-lactamase inactivators, wherein a Ser70 acylenzyme derived from these inactivators chemically partitions into a hydrolytically stable state [47]. Moreover, the phenomenon of a stabilized Ser70 acyl-enzyme to account for steady-state kinetic anomalies, seen for certain $\beta$-lactamases in the presence of penicillin substrates having a large $7 \beta$-arylamide substituent, was likewise proven by Cartwright, Tan, and Fink [48, 49]. Last, use of a deacylation-impaired $\beta$-lactamase mutant wherein the active site glutamate Glu166 is replaced by glutamine, allowed crystallographic isolation of the acyl-enzyme [50, 51].

As simple cephalosporin structures - those having a hydrogen in the 7a-position and not the $7 a$-methoxy substituent, as is found in cefoxitin - are reasonable $\beta$-lactamase substrates, the key mechanistic issue is the basis for the perturbation by the 7a-methoxy substituent of the customary active site events of acyl-enzyme formation and hydrolysis. A consensus as to what these customary events are, with respect to the key functional groups presented within the active site, has proven to be a challenging problem. The more challenging of the two half reactions to understand has been acylation. As the $\beta$-lactam is a cyclic amide, the acylation reaction requires firstly general base catalysis to engage the serine toward tetrahedral formation, followed by general acid catalysis to drive the collapse (by $\mathrm{N}$-protonation) of this tetrahedral intermediate to the acyl-enzyme. Careful determination of the $\mathrm{pH}$ dependence of class A $\beta$-lactamase catalysis, such as the data presented by Escobar et al. [52], shows a near neutral $\mathrm{pH}$ optimum flanked by an ascending limb ( $\mathrm{p} K_{\mathrm{a}}$ of approximately 6.2 on $k_{\text {cat }} / K_{\mathrm{M}}$ ) and a descending $\operatorname{limb}\left(\mathrm{p} K_{\mathrm{a}}\right.$ of approximately 8.5 on $k_{\mathrm{cat}} / K_{\mathrm{M}}$ ). These values fit well with the presumption that the lower $\mathrm{p} K_{\mathrm{a}}$ is ionization to form the general base and the higher $\mathrm{p} K_{\mathrm{a}}$ is ionization to dissipate the general acid. The assignment of the lower $\mathrm{p} K_{\mathrm{a}}$ to Glu166 is consistent with Glu166 mutagenesis, and especially with the observation by Cartwright, Tan and Fink [45] that this $\mathrm{p} K_{\mathrm{a}}$ is temperature independent. This characteristic is known to coincide with the carboxylic acid, a functional group having a small heat of ionization [45]. A decisive experiment supporting the assignment of the $\mathrm{p} K_{\mathrm{a}}$ of the basic limb to Lys73 came from evaluation of the $\mathrm{pH}$ dependence of the NMR spectrum of a $\beta$-lactamase incorporating a thialysine (the conjugate acid of which is weaker than the conjugate acid of lysine) 
replacement for Lys73 [53]. This study directly assigns this $\mathrm{p} K_{\mathrm{a}}$ to this lysine, consistent with the observation that this $\mathrm{p} K_{\mathrm{a}}$ exhibits the large heat of ionization characteristic of lysines [45]. However, since these assignments derive from $k_{\text {cat }} / K_{\mathrm{M}}$ measurement and hence pertain only to the free enzyme, the microscopic alterations within the active site upon $\beta$ lactam substrate entry and formation of the Michaelis complex may be more complex. Indeed, the prospect of microscopic perturbation within the Michaelis complex is to be expected, since the bound $\beta$-lactam substrate removes both Glu166 and Lys73 from solvent contact. The certainty that such alterations occur-and multiple pathways are enabled-is supported by a host of experiments, only some of which are here summarized. First, as noted ruefully by Leitz et al. [54], the $\mathrm{pH}$ dependence of $k_{\mathrm{cat}} / K_{\mathrm{M}}$ for the serine $\beta$-lactamases (and their mutants) is substrate dependent (as much as a $1.5 \mathrm{pH}$ unit variation between different substrates). Second, while the Glu166Ala $\beta$-lactamase is severely incapacitated with respect to deacylation, this mutant enzyme nonetheless remains capable of acylation. The loss of the deacylation ability in the absence of this glutamate (such as in the Glu166Ala mutant) is fully consistent with the evolutionary appearance of this glutamate in the serine $\beta$ lactamases as compared to the PBPs. Likewise, the retention of the ability for acylation in the Glu166Ala mutant is consistent with an alternative pathway, such as one using Lys73 as a general base in the absence of Glu166, just as occurs during the PBP acylation halfreaction [55]. Last, the likelihood of full interplay of the acid-base active site ensemble is attested by the complexity of interpretation presented by the elegant experimental studies of Leitz et al. on the Lys73Ala $\beta$-lactamase mutant [54]. This enzyme shows a substantial alkaline shift for both $\mathrm{p} K_{\mathrm{a}}$ values, a substantial (200-fold) reduction in $k_{\text {cat }} / K_{\mathrm{M}}$ at the $\mathrm{pH}$ optimum for penicillins, and a very substantial reduction (10,000-fold) in $k_{\text {cat }} / K_{\mathrm{M}}$ at the pH optimum for cephalosporins. Moreover, whereas for the wild type enzyme acylation is ratelimiting for both substrates, in the Lys73Ala mutant acylation remained rate-limiting for cephalosporin substrates but deacylation was rate-limiting for the penicillins. The interpretation of different kinetic data led Fink and his colleagues to two important conclusions, both of which we believe have withstood the test of time. The first is that "both Glu166 and Lys73 are important to each other in terms of maintaining the optimum electrostatic environment for fully efficient catalytic activity" [54]. The second is the likelihood that "significant differences in the mechanism for catalysis of penicillins compared to cephalosporins" exist [54].

With respect to this second conclusion, it is useful to be reminded of the purpose of the $\beta$ lactamase enzyme. In contrast to the PBPs, which accomplish a single task within a very limited substrate spectrum, the $\beta$-lactamases must recognize and embrace a plurality of substrates. These substrates now include the nearly planar (with respect to the annulated ring to the $\beta$-lactam) cephalosporins, the moderately non-planar penicillins, and the acutely nonplanar carbapenems. Toward the objective of enabling some level of ability for $\beta$-lactam hydrolysis, encompassing all classes of $\beta$-lactam antibiotic structure, the conceptualization of an electrostatically engaged Glu166 and Lys73 pair capable of Glu166 general base catalysis for Ser70 acylation by some substrates and Lys 73 general base catalysis for Ser70 acylation by others, is a reasonable (and possibly evolutionarily mandated) circumstance. The IR studies by Fink and colleagues strongly suggest that the $\beta$-lactam ring sub-structure, regardless of the $\beta$-lactam antibiotic class to which they belong, form very similar 
complexes with the oxyanion hole [40]. While this implicates very similar trajectories toward formation of the first tetrahedral species, the collapse of this tetrahedral (with its requirement for general acid protonation of the nitrogen) may demand different prototopic states and active site amino acid positioning, from one $\beta$-lactam class to another. For some, Glu166-driven acylation may be productive, while for others Lys73-driven acylation may be productive. Recent and complementary further perspectives on the microscopic events of serine $\beta$-lactamase catalysis are given elsewhere, from the vantage of computational study of the TEM $\beta$-lactamase mechanism [56] and from experimental study of the extended spectrum serine $\beta$-lactamases (ESBLs), $\beta$-lactamases which recognize new generation $\beta$ lactams and therefore confer greater bacterial resistance to these $\beta$-lactams [57-59].

\section{STRUCTURAL ASPECTS OF THE $\beta$-LACTAMASE ACYL-ENZYME}

The additional distinguishing feature between the PBP and $\beta$-lactamase active sites is the presence of water in the latter. Indeed, crystallographic studies show a single water molecule - the hydrolytic water molecule - as a proton bridge from the Glu166/Lys73 dyad to the nucleophilic Ser70 hydroxyl. $\beta$-Lactam occupancy of the oxyanion hole shields these functionalities from solvent, and positions Ser70 for nucleophilic addition to the $\beta$-face of the $\beta$-lactam carbonyl. An obvious possibility to account for the very slow acylation and deacylation half-reactions of cefoxitin as a substrate for serine $\beta$-lactamases is steric clash of its unprecedented $7 a$-methoxy substituent with this catalytic machinery. An identical argument would hold for the $\beta$-lactamase-resistant $6 a$-(a-hydroxyethyl) naturally-occurring carbapenems (exemplified by imipenem). This hypothesis was put to a test by the design and synthesis of the 6a-hydroxymethylpenams [60] depicted in Fig. (4). The particular question prompting the design of this penicillin class was whether the mechanistic role of the hydroxyl of the 6a-substituent was displacement of the hydrolytic water from its location between the Glu166/Lys73 dyad and Ser70. Were this to occur, one mechanistic outcome would be acylation of Ser70 to a stable acyl-enzyme, incapable of progressing through the deacylation half-reaction in the absence of this water. The behavior of the $6 \mathrm{a}-$

hydroxymethylpenam with the TEM $\beta$-lactamase was more complex: this compound indeed inactivated the $\beta$-lactamase, but in a kinetically biphasic process $\left(k_{\text {inact }}=0.06 \mathrm{~min}^{-1}, K_{\mathrm{I}}=\right.$ $36 \mu \mathrm{M})$ corresponding to a partitioning of this compound between hydrolysis and ultimately enzyme inactivation (partition ratio of 28). The isolated, inactivated $\beta$-lactamase subsequently slowly recovered its full activity $\left(t_{1 / 2}=11 \mathrm{~h}\right)$. The presumption that the basis for this inactivation was accumulation into a stable (albeit not indefinitely so) acyl-enzyme was confirmed by crystallography [61]. A line structure for this Ser70 acyl-enzyme is shown in Fig. (5). The prediction that the 6a-hydroxyalkyl penam represented a general concept for inhibitor design was proven by examination of this class with the NMC-A class A $\beta$ lactamase, an extended-spectrum $\beta$-lactamase capable of imipenem hydrolysis. Whereas the $6 a$-hydroxymethylpenam was a substrate for the NMC-A $\beta$-lactamase, the 6a-[(a-hydroxya-methyl)ethyl]penam functioned only as an irreversible inhibitor of this enzyme. The primary effect of the hydroxyl on the 6a-substituent was not displacement of the hydrolytic water, but rather its subtle dislocation within the active site $[62,63]$. The structure of this acyl-enzyme is shown as Fig. (6). The hydrolytic water (dots) is moved away from the acylenzyme carbonyl, to within hydrogen bonding distance of the 6a-hydroxyl, Lys73, Asn132 
and Glu166. Moreover, approach of this water to the carbonyl is impeded by a methyl group of the $6 a$-substituent. A very similar outcome is observed for the cefoxitin-derived acylenzyme obtained with the CTX-M $\beta$-lactamase: a $1 \AA$ movement of the hydrolytic water coinciding with steric impediment of its approach to the acyl-enzyme [57].

\section{CONCLUSION}

In the thirty years following mechanistic recognition of the acyl-enzymes of the serine $\beta$ lactamases as catalytic intermediates, these acyl-enzymes are now seen to occupy a central position in the understanding of $\beta$-lactamase kinetics, substrate-specificity, resistance mutation, and mechanism-based inactivation. Notwithstanding their recent discovery-and likewise, the discovery of the acyl-enzymes of the penicillin binding proteins-these two acyl-enzyme classes are now recognized as ancient and intimately evolutionarily intertwined. The understanding of the bases defining their structural commonality, and of the counterpoint created by the addition to the PBP of the Glu166-containing loop and the entry into the active site of a hydrolytic water molecule so as to enable a hydrolytic deacylation half-reaction (and thus $\beta$-lactam destruction), has been accomplished by the patient and careful interrogation of each mechanistic component. Each method of interrogationincluding low temperature kinetics and intermediate trapping [45, 46, 49], site-specific mutagenesis [52, 54, 64-69], ESR [70] and IR spectroscopy [40], enzyme crystallization [51], and inhibitor mechanism [71] — has illuminated points of commonality and of difference. While there remain numerous unanswered questions [72] we are today better prepared to address the continuing challenge of new antibiotic development, from the these efforts to understand the $\beta$-lactamase acyl-enzyme as the central mechanistic entity in $\beta$ lactamase-catalyzed substrate hydrolysis, and in $\beta$-lactamase mechanism-based inactivation.

\section{DEDICATION}

This essay is dedicated to the memory of Tony Fink [73]. We shared with Tony a fascination with the mechanism of the serine $\beta$-lactamases, and we-like so many others- always found our curiosity rewarded by the rigor of his experimental craft and the eclectic breadth of his intellect. This essay captures only a small portion of our gratitude.

\section{REFERENCES}

[1]. Kresge N; Simoni RD; Hill RL Selman Waksman: the Father of Antibiotics. J. Biol. Chem, 2005, 279, e7-e8.

[2]. Lee B Conformation of penicillin as a transition-state analog of the substrate of peptidoglycan transpeptidase. J. Mol. Biol, 1971, 61, 463-469. [PubMed: 4257008]

[3]. Pratt RF Functional evolution of the serine $\beta$-lactamase active site. J. Chem. Soc., Perkin Trans. I, 2002, 2, 851-861.

[4]. Kresge N; Simoni RD; Hill RL Penicillin binding in bacteria: the work of jack 1. strominger. J. Biol. Chem, 2007, 282, e25-e27.

[5]. Abraham E Selective reminiscences of $\beta$-lactam antibiotics: early research on penicillin and cephalosporins. Bioessays, 1990, 12, 601-606. [PubMed: 2080915]

[6]. Fisher JF; Meroueh SO; Mobashery S Bacterial resistance to $\beta$-lactam antibiotics: compelling opportunism, compelling opportunity. Chem. Rev, 2005, 105, 395-424. [PubMed: 15700950] 
[7]. Knox JR Before Our Time: Early $\beta$-Lactamase Papers and the People Who Wrote Them, Frére JM; Ed.; The $\beta$-Lactamases. Nova Science Publishers: New York, 2009.

[8]. Sutcliffe JG Nucleotide sequence of the ampicillin resistance gene of $E$. coli plasmid pBR322. Proc. Natl. Acad. Sci. USA, 1978, 75, 3737-3741. [PubMed: 358200]

[9]. Ambler RP; Scott GK Partial amino acid sequence of penicillinase coded by E. coli plasmid R6K. Proc. Natl. Acad. Sci. USA, 1978, 75, 3732-3736. [PubMed: 358199]

[10]. Yocum RR; Waxman DJ; Rasmussen JR; Strominger JL Mechanism of penicillin action: penicillin and substrate bind covalently to the same active site serine in two bacterial D-alanine carboxypeptidases. Proc. Natl. Acad. Sci. USA, 1979, 76, 2730-2734. [PubMed: 111240]

[11]. Waxman DJ; Strominger JL Sequence of active site peptides from the penicillin-sensitive Dalanine carboxypeptidase of Bacillus subtilis. Mechanism of penicillin action and sequence homology to $\beta$-lactamases. J. Biol. Chem, 1980, 255, 3964-3976. [PubMed: 6768745]

[12]. Stapley EO; Jackson M; Hernandez S; Zimmerman SB; Currie SA; Mochales S; Mata JM; Woodruff HB; Hendlin D Cephamycins, a new family of $\beta$-lactam antibiotics. Antimicrob. Agents Chemother, 1972, 2, 122-131. [PubMed: 4790552]

[13]. Albers-Schoenberg H; Arison BH; Hensens OD; Hirshfield J; Hoogsteen K; Kaczka EA; Rhodes RE; Kahan JS; Kahan FM; Ratcliffe RW; Walton E; Ruswinkle LJ; Morin RB; Christensen BG Structure and absolute configuration of thienamycin. J. Am. Chem. Soc, 1978, 100, 6491-6499.

[14]. Brown AG; Butterworth D; Cole M; Hanscomb G; Hood JD; Reading C; Rolinson GN Naturallyoccurring $\beta$-lactamase inhibitors with antibacterial activity. J. Antibiot. (Tokyo), 1976, 29, 668669. [PubMed: 950324]

[15]. Howarth TT; Brown AG; King TJ Clavulanic acid, a novel $\beta$-lactam isolated from Streptomyces clavuligerus; x-ray crystal structure analysis. J. Chem. Soc., Chem. Commun, 1976, 266-267.

[16]. Pratt RF; Loosemore MJ 6 $\beta$-Bromopenicillanic acid, a potent $\beta$-lactamase inhibitor. Proc. Natl. Acad. Sci. USA, 1978, 75, 4145-4149. [PubMed: 212736]

[17]. Cartwright SJ; Coulson AF A semi-synthetic penicillinase inactivator. Nature, 1979, 278, 360361. [PubMed: 218114]

[18]. Knott-Hunziker V; Orlek BS; Sammes PG; Waley SG 6 $\beta$-Bromopenicillanic acid inactivates $\beta$ lactamase I. Biochem. J, 1979, 177, 365-367. [PubMed: 218563]

[19]. Moore BA; Brammer KW 6 $\beta$-Iodopenicillanic acid (UI-38,006), a $\beta$-lactamase inhibitor that extends the antibacterial spectrum of $\beta$-lactam compounds: initial bacteriological characterization. Antimicrob. Agents Chemother, 1981, 20, 327-331. [PubMed: 6272628]

[20]. Wise R; Andrews JM; Patel N 6- $\beta$-bromo- and 6- $\beta$-iodo penicillanic acid, two novel $\beta$-lactamase inhibitors. J. Antimicrob. Chemother, 1981, 7, 531-536. [PubMed: 6267005]

[21]. English AR; Retsema JA; Girard AE; Lynch JE; Barth WE CP-45,899, a $\beta$-lactamase inhibitor that extends the antibacterial spectrum of $\beta$-lactams: initial bacteriological characterization. Antimicrob. Agents Chemother, 1978, 14, 414-419. [PubMed: 309306]

[22]. Knowles JR Penicillin resistance: the chemistry of $\beta$-lactamase inhibition. Acc. Chem. Res, 1985, 18, 97-104.

[23]. Herzberg O; Moult J Bacterial resistance to $\beta$-lactam antibiotics: crystal structure of $\beta$-lactamase from $S$. aureus PC1 at $2.5 \AA$ resolution. Science, 1987, 236, 694-701. [PubMed: 3107125]

[24]. Kelly JA; Moews PC; Knox JR; Frere JM; Ghuysen JM Penicillin target enzyme and the antibiotic binding site. Science, 1982, 218, 479-481. [PubMed: 7123246]

[25]. Kelly JA; Dideberg O; Charlier P; Wery JP; Libert M; Moews PC; Knox JR; Duez C; Fraipont C; Joris B; Dusart J; Frère JM; Ghuysen JM On the origin of bacterial resistance to penicillin: comparison of a $\beta$-lactamase and a penicillin target. Science, 1986, 231, 1429-1431. [PubMed: 3082007]

[26]. Knox JR; Moews PC; Frere JM Molecular evolution of bacterial $\beta$-lactam resistance. Chem. Biol, 1996, 3, 937-947. [PubMed: 8939710]

[27]. Massova I; Mobashery S Kinship and diversification of bacterial penicillin-binding proteins and $\beta$-lactamases. Antimicrob. Agents Chemother, 1998, 42, 1-17. [PubMed: 9449253]

[28]. Massova I; Mobashery S Structural and mechanistic aspects of evolution of $\beta$-lactamases and penicillin-binding proteins. Curr. Pharm. Des, 1999, 5, 929-937. [PubMed: 10539997] 
[29]. Buynak JD Cutting and stitching: the cross-linking of peptidoglycan in the assembly of the bacterial cell wall. ACS Chem. Biol, 2007, 2, 602-605. [PubMed: 17894443]

[30]. Maveyraud L; Golemi D; Kotra LP; Tranier S; Vakulenko S; Mobashery S; Samama JP Insights into class D $\beta$-lactamases are revealed by the crystal structure of the OXA10 enzyme from Pseudomonas aeruginosa. Structure, 2000, 8, 1289-1298. [PubMed: 11188693]

[31]. Murphy BP; Pratt RF Evidence for an oxyanion hole in serine $\beta$-lactamases and DD-peptidases. Biochem. J, 1988, 256, 669-672. [PubMed: 3066349]

[32]. Christensen H; Martin MT; Waley SG $\beta$-Lactamases as fully efficient enzymes: determination of all the rate constants in the acyl-enzyme mechanism. Biochem. J, 1990, 266, 853-861. [PubMed: 2158301]

[33]. Fisher JF; Knowles JR Bacterial resistance to the $\beta$-lactams: the $\beta$-lactamases. Annu. Rev. Med. Chem, 1978, 13, 239-248.

[34]. Pratt RF; Anderson EG; Odeh I Certain monocyclic $\beta$-lactams are $\beta$-lactamase substrates: norcardicin A and desthiobenzylpenicillin. Biochem. Biophys. Res. Commun, 1980, 93, 12661273. [PubMed: 6772177]

[35]. Fisher J; Charnas RL; Knowles JR Kinetic studies on the inactivation of E. coli RTEM $\beta$ lactamase by clavulanic acid. Biochemistry, 1978, 17, 2180-2184. [PubMed: 352394]

[36]. Charnas RL; Fisher J; Knowles JR Chemical studies on the inactivation of E. coli RTEM $\beta$ lactamase by clavulanic acid. Biochemistry, 1978, 17, 2185-2189. [PubMed: 352395]

[37]. Onishi HR; Daoust DR; Zimmerman SB; Hendlin D; Stapley EO Cefoxitin, a semisynthetic cephamycin antibiotic: resistance to $\beta$-lactamase inactivation. Antimicrob. Agents Chemother, 1974, 5, 38-48. [PubMed: 4599124]

[38]. Gadebusch HH; Stapley EO; Zimmerman SB The discovery of cell wall active antibacterial antibiotics. Crit. Rev. Biotechnol, 1992, 12, 225-243. [PubMed: 1633621]

[39]. Fisher J; Belasco JG; Khosla S; Knowles JR $\beta$-Lactamase proceeds via an acyl-enzyme intermediate: interaction of the E. coli RTEM enzyme with cefoxitin. Biochemistry, 1980, 19, 2895-2901. [PubMed: 6994800]

[40]. Hokenson MJ; Cope GA; Lewis ER; Oberg KA; Fink AL Enzyme-induced strain/distortion in the ground-state ES complex in $\beta$-lactamase catalysis revealed by FTIR. Biochemistry, 2000, 39, 6538-6545. [PubMed: 10828970]

[41]. Wilkinson AS; Ward S; Kania M; Page MG; Wharton CW Multiple conformations of the acylenzyme formed in the hydrolysis of methicillin by Citrobacter freundii $\beta$-lactamase: a timeresolved FTIR spectroscopic study. Biochemistry, 1999, 38, 3851-3856. [PubMed: 10194295]

[42]. Wilkinson AS; Bryant PK; Meroueh SO; Page MG; Mobashery S; Wharton CW A dynamic structure for the acylenzyme species of the antibiotic aztreonam with the Citrobacter freundii $\beta$ lactamase revealed by infrared spectroscopy and molecular dynamics simulations. Biochemistry, 2003, 42, 1950-1957. [PubMed: 12590581]

[43]. Fink AL; Geeves MA Cryoenzymology: the study of enzyme catalysis at subzero temperatures. Methods Enzymol, 1979, 63, 336-370. [PubMed: 41158]

[44]. Cartwright SJ; Waley SG Cryoenzymology of $\beta$-lactamases. Biochemistry, 1987, 26, 5329-5337. [PubMed: 3118942]

[45]. Cartwright SJ; Tan AK; Fink AL Trapping the acyl-enzyme intermediate in $\beta$-lactamase I catalysis. Biochem. J, 1989, 263, 905-912. [PubMed: 2512916]

[46]. Virden R; Tan AK; Fink AL Cryoenzymology of staphylococcal $\beta$-lactamase: trapping a serine-70-linked acyl-enzyme. Biochemistry, 1990, 29, 145-153. [PubMed: 2108714]

[47]. Fisher J; Charnas RL; Bradley SM; Knowles JR Inactivation of the RTEM $\beta$-lactamase from $E$. coli. Interaction of penam sulfones with enzyme. Biochemistry, 1981, 20, 2726-2731. [PubMed: 7018564]

[48]. Cartwright SJ; Fink AL Isolation of a covalent intermediate in $\beta$-lactamase I catalysis. FEBS Lett, 1982, 137, 186-188. [PubMed: 6800840]

[49]. Tan AK; Fink AL Identification of the site of covalent attachment of nafcillin, a reversible suicide inhibitor of $\beta$-lactamase. Biochem. J, 1992, 281, 191-196. [PubMed: 1731755]

Curr Protein Pept Sci. Author manuscript; available in PMC 2019 December 10. 
[50]. Strynadka NC; Adachi H; Jensen SE; Johns K; Sielecki A; Betzel C; Sutoh K; James MN G. Molecular structure of the acyl-enzyme intermediate in $\beta$-lactam hydrolysis at $1.7 \AA$ resolution. Nature, 1992, 359, 700-705. [PubMed: 1436034]

[51]. Knox JR; Moews PC; Escobar WA; Fink AL A catalytically-impaired class A $\beta$-lactamase: $2 \AA$ crystal structure and kinetics of the Bacillus licheniformis E166A mutant. Protein Eng, 1993, 6, 11-18. [PubMed: 8433965]

[52]. Escobar WA; Tan AK; Lewis ER; Fink AL Site-directed mutagenesis of glutamate-166 in $\beta$ lactamase leads to a branched path mechanism. Biochemistry, 1994, 33, 7619-7626. [PubMed: 7912106]

[53]. Golemi-Kotra D; Meroueh SO; Kim C; Vakulenko SB; Bulychev A; Stemmler AJ; Stemmler TL; Mobashery $S$ The importance of a critical protonation state and the fate of the catalytic steps in class A $\beta$-lactamases and penicillin-binding proteins. J. Biol. Chem, 2004, 279, 34665-34673. [PubMed: 15152012]

[54]. Lietz EJ; Truher H; Kahn D; Hokenson MJ; Fink AL Lysine-73 is involved in the acylation and deacylation of $\beta$-lactamase. Biochemistry, 2000, 39, 4971-4981. [PubMed: 10819961]

[55]. Shi Q; Meroueh SO; Fisher JF; Mobashery S Investigation of the mechanism of the cell wall DDcarboxypeptidase reaction of penicillin-binding protein 5 of $E$. coli by QM/MM calculations. J. Am. Chem. Soc, 2008, 130, 9293-9303. [PubMed: 18576637]

[56]. Meroueh SO; Fisher JF; Schlegel HB; Mobashery S Ab initio QM/MM study of class A $\beta$ lactamase acylation: dual participation of Glu166 and Lys73 in a concerted base promotion of Ser70. J. Am. Chem. Soc, 2005, 127, 15397-15407. [PubMed: 16262403]

[57]. Chen Y; Shoichet B; Bonnet R Structure, function, and inhibition along the reaction coordinate of CTX-M $\beta$-lactamases. J. Am. Chem. Soc, 2005, 127, 5423-5434. [PubMed: 15826180]

[58]. Chen Y; Minasov G; Roth TA; Prati F; Shoichet BK The deacylation mechanism of AmpC $\beta$ lactamase at ultrahigh resolution. J. Am. Chem. Soc, 2006, 128, 2970-2976. [PubMed: 16506777]

[59]. Chen Y; Bonnet R; Shoichet BK The acylation mechanism of CTX-M $\beta$-lactamase at $0.88 \AA$ resolution. J. Am. Chem. Soc, 2007, 129, 5378-5380. [PubMed: 17408273]

[60]. Miyashita K; Massova I; Taibi P; Mobashery S Design, synthesis, and evaluation of a potent mechanism-based inhibitor for the TEM $\beta$-lactamase with implications for the enzyme mechanism. J. Am. Chem. Soc, 1995, 117, 11055-11059.

[61]. Maveyraud L; Massova I; Birck C; Miyashita K; Samama JP; Mobashery S Crystal structure of 6a-(hydroxymethyl)penicil lanate complexed to the TEM-1 $\beta$-lactamase from E. coli: evidence on the mechanism of action of a novel inhibitor designed by a computer-aided process. J. Am. Chem. Soc, 1996, 118, 7435-7440.

[62]. Mourey L; Miyashita K; Swaren P; Bulychev A; Samama JP; Mobashery S Inhibition of the NMC-A $\beta$-lactamase by a Penicillanic acid derivative. J. Am. Chem. Soc, 1998, 120, 9382-9383.

[63]. Golemi D; Maveyraud L; Ishiwata A; Tranier S; Miyashita K; Nagase T; Massova I; Mourey L; Samama JP; Mobashery S 6-(Hydroxyalkyl)penicillanates as probes for mechanisms of $\beta$ lactamases. J. Antibiot. (Tokyo), 2000, 53, 1022-1027. [PubMed: 11132946]

[64]. Ellerby LM; Escobar WA; Fink AL; Mitchinson C; Wells JA The role of lysine-234 in $\beta$ lactamase catalysis probed by site-directed mutagenesis. Biochemistry, 1990, 29, 5797-5806. [PubMed: 1974463]

[65]. Escobar WA; Tan AK; Fink AL Site-directed mutagenesis of $\beta$-lactamase leading to accumulation of a catalytic intermediate. Biochemistry, 1991, 30, 10783-10787. [PubMed: 1681903]

[66]. Escobar WA; Miller J; Fink AL Effects of site-specific mutagenesis of tyrosine 105 in a class A $\beta$-lactamase. Biochem. J, 1994, 303, 555-558. [PubMed: 7980417]

[67]. Viadiu H; Osuna J; Fink AL; Soberon X A new TEM $\beta$-lactamase double mutant with broadened specificity reveals substrate-dependent functional interactions. J. Biol. Chem, 1995, 270, 781787. [PubMed: 7822311]

[68]. Osuna J; Viadiu H; Fink AL; Soberon X Substitution of Asp for Asn at position 132 in the active site of TEM $\beta$-lactamase. Activity toward different substrates and effects of neighboring residues. J. Biol. Chem, 1995, 270, 775-780. [PubMed: 7822310] 
[69]. Lewis ER; Winterberg KM; Fink AL A point mutation leads to altered product specificity in $\beta$ lactamase catalysis. Proc. Natl. Acad. Sci. USA, 1997, 94, 443-447. [PubMed: 9012802]

[70]. Calciano LJ; Escobar WA; Millhauser GL; Miick SM; Rubaloff J; Todd AP; Fink AL Side-chain mobility of the $\beta$-lactamase A state probed by ESR spectroscopy. Biochemistry, 1993, 32, 56445649. [PubMed: 8389188]

[71]. Rizwi I; Tan AK; Fink AL; Virden R Clavulanate inactivation of $S$. aureus $\beta$-lactamase. Biochem. J, 1989, 258, 205-209. [PubMed: 2494991]

[72]. Pratt RF Substrate specificity of bacterial DD-peptidases (penicillin-binding proteins). Cell. Mol. Life Sci, 2008, 65, 2138-2155. [PubMed: 18408890]

[73]. Goto Y Anthony L Fink 1943-2008. Biochim. Biophys. Acta, 2008, 1784, 1127-1129.

Curr Protein Pept Sci. Author manuscript; available in PMC 2019 December 10. 


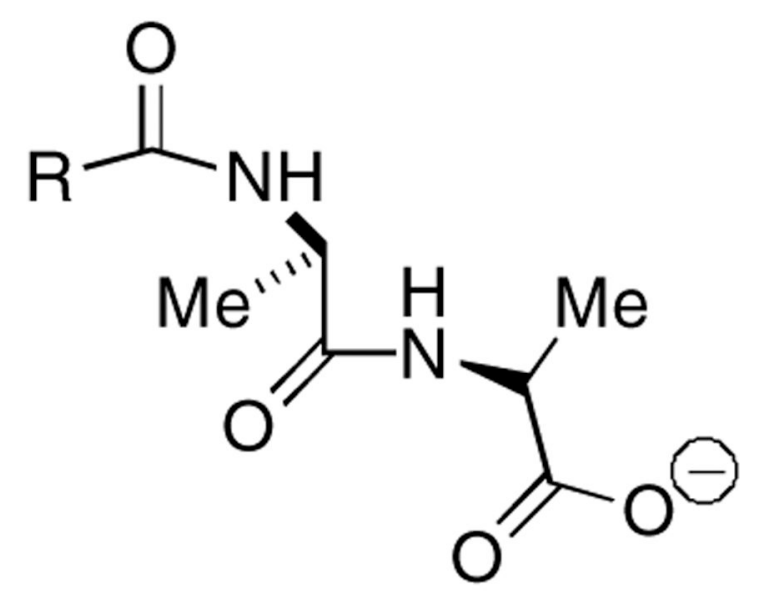

N-Acyl-D-Ala-D-Ala

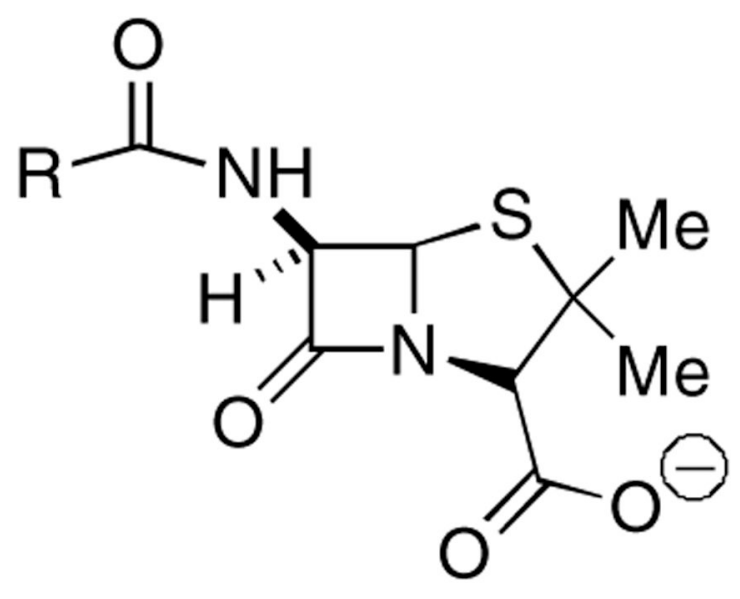

$N$-Acyl-6-Aminopenicillanate

Fig. (1).

Comparison of the structures of an N-acyl D-Ala-D-Ala dipeptide (left) and an N-acyl penicillin (right). 


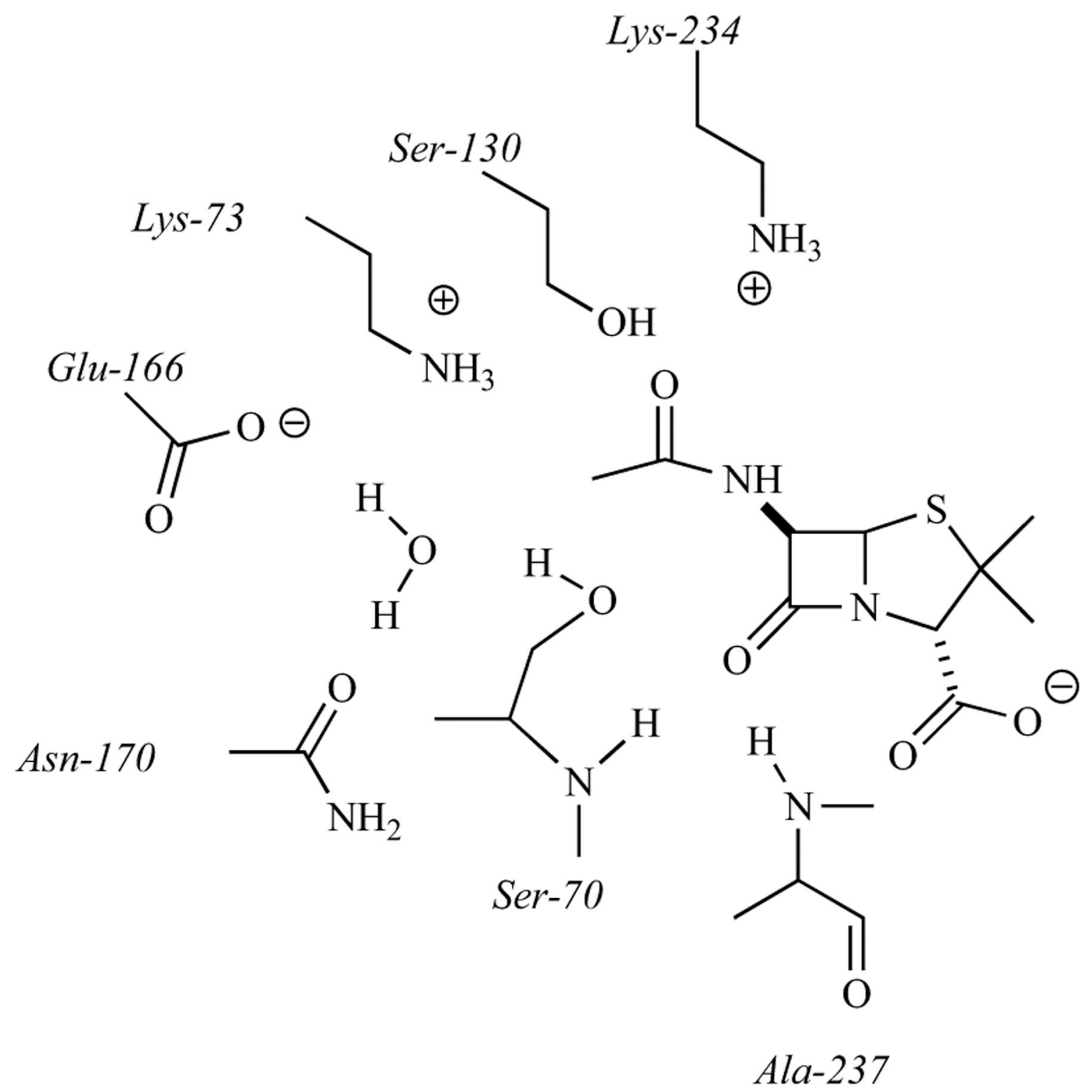

Fig. (2).

Two-dimensional representation of key active site residues, and the hydrolytic water, in a class A $\beta$-lactamase (TEM numbering) arranged around a penicillin substrate. 

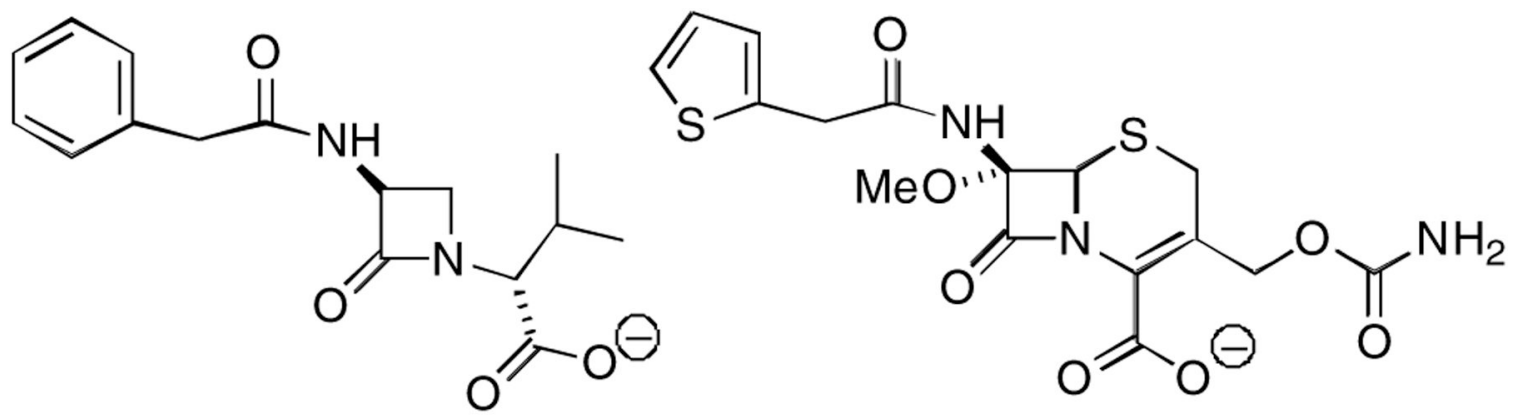

"Desthio" Benzylpenicillin

Cefoxitin

Fig. (3).

Structures of desthio-benzylpenicillin and cefoxitin, a 7a-methoxy-substituted cephalosporin. 

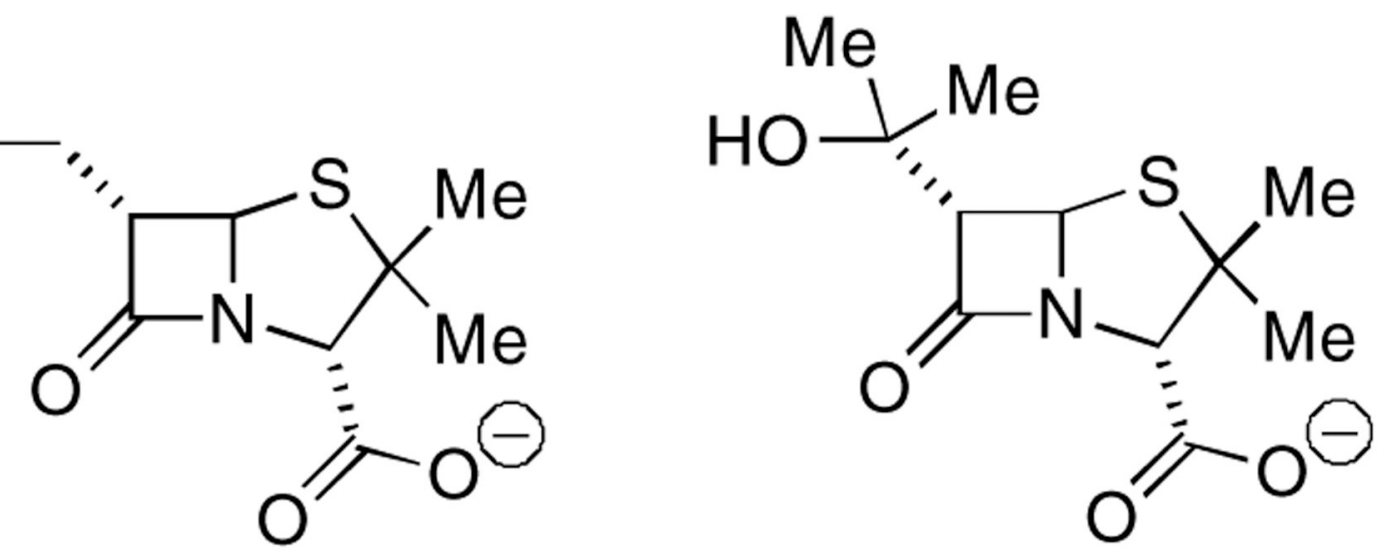

Fig. (4).

Structures of 6a-hydroxymethylpenam (left) and 6a-[(a-hydroxy-a-methyl)ethyl]penam (right), designed as inhibitors of the serine $\beta$-lactamases. 


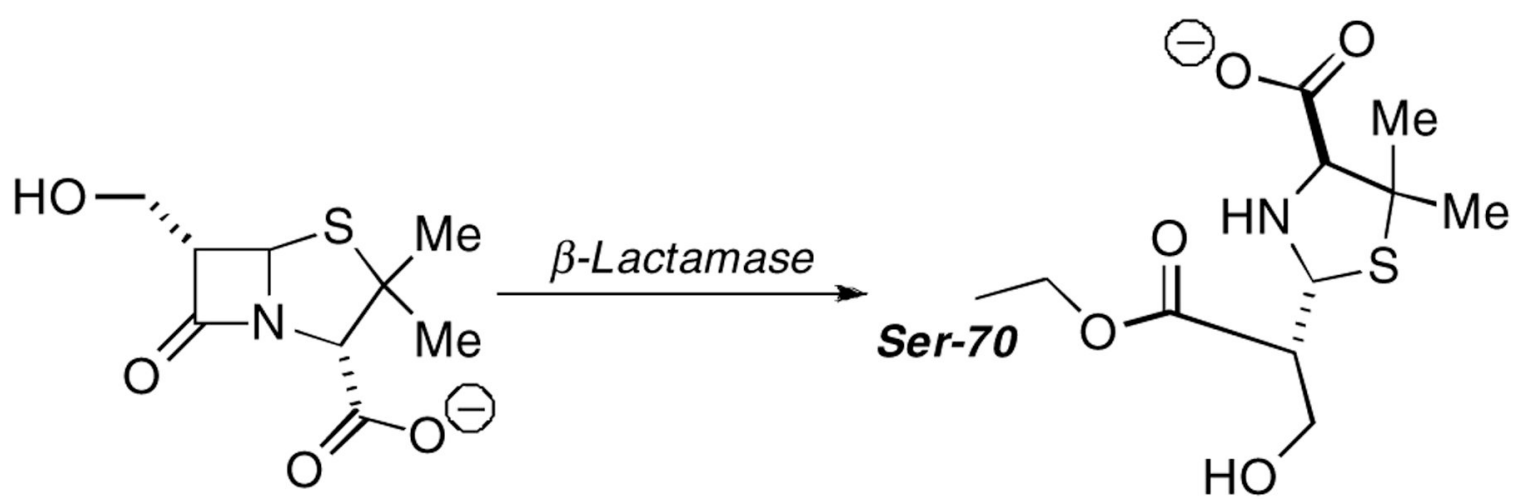

Fig. (5).

Ser70 $\beta$-lactamase acyl-enzyme formed from the 6a-hydroxymethyl-substituted penam inhibitor. 


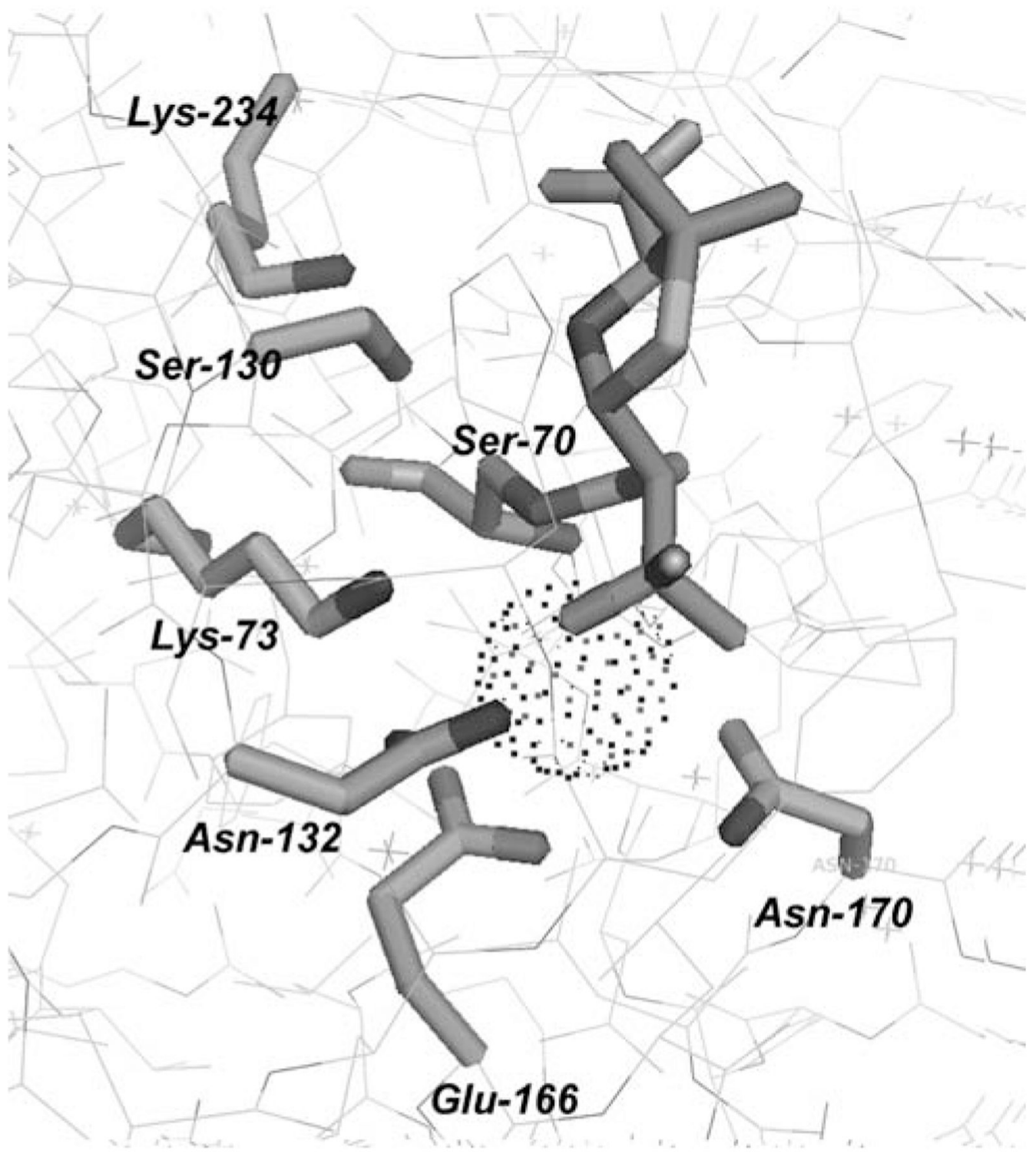

Fig. (6).

Structure of the NMC-A $\beta$-lactamase acyl-enzyme derived from 6a-[(a-hydroxy-amethyl)ethyl]penam (1.9 ̊ resolution, PDB Code 1BUL). The hydrolytic water is shown as a dotted spherical surface. 